\title{
CDISC SEND Terminology
}

National Cancer Institute

\section{Source}

National Cancer Institute. CDISC SEND Terminology. NCI Thesaurus. Code C77526.

The terminology subset that includes terms relevant to the Clinical Data Interchange Standards Consortium (CDISC) Standard for Exchange of Non-clinical Data (SEND) group. 